Open Access

\title{
Exploitation of architectural knowledge and innovation
}

Junghee Han

Correspondence:

hjh0037@hongik.ac.kr

Graduate School of Smart City

Science Management, Hongik

University, Room 306-2, Sejong-ro,

Jochiwon, Sejong City, South Korea

\begin{abstract}
Knowledge across several segments appears to be a necessary ingredient to innovation in the case of an architectural shift. Innovative firms utilize their knowledge stock to confront the competitive market. This paper demonstrates that exploitation of accumulated knowledge leads to architectural innovation. Ironically, in the new development of products with a short life cycle, when a firm discards its accumulated knowledge, innovation can be the result. After architecture technology is fully emerged, the utilization of architectural knowledge is one of the critical innovations. Based on the findings, architectural changing from sequential rotation flip into simultaneous vibration feeding flip in Pick and Place is a result of discarding the existing accumulated knowledge. This paper enhances our understanding of how architectural innovation occurs.
\end{abstract}

Keywords: Architectural Knowledge, Architectural innovation, Radical innovation, Incremental innovation, OSAT

\section{Introduction}

In today's rapidly changing market landscape, regardless of any specific industry, innovation has been regarded as a key to survival and firm growth. So, firms have been pursuing innovation ceaselessly (Dosi, 1982; Freeman, 1982). Technological lifecycle classifies innovation as incremental or radical. This research aims at showing the importance of existing knowledge stock destruction and exploitation in order to catch the newness. When a firm develops a new products through incremental improvements to the functions of the existing instruments, I see it as innovation output. A company's survival depends on its ability to manage innovation. While numerous innovations involve only step by step changes within a particular module of a product or process, in some cases, innovations can bring architectural changes and redefine the overall design of the product or process.

All innovations happen in order to meet the market demand (i.e., enhancing current core competence and capabilities, life extension with respect to cost) regardless of incremental or radical change. Choosing the innovation types is a critical strategy decision since innovation types can provide different customer values. Firms are more likely to prefer incremental innovation rather radical innovation in terms of diminishing the risks, the easy use of existing knowledge (Han and Ko, 2017; Raviola and Dubini, 2015 Hommels et al., 2007; Henderson and Clark, 1990; Bozdogan et al., 1998). Choosing the innovation types can be relied on the firms' knowledge stock (Veronica et al., 2017). Cognitive dimensions, knowledge driven strategy, and absorptive

(c) The Author(s). 2017 Open Access This article is distributed under the terms of the Creative Commons Attribution 4.0 International License (http://creativecommons.org/licenses/by/4.0/), which permits unrestricted use, distribution, and reproduction in any medium, provided you give appropriate credit to the original author(s) and the source, provide a link to the Creative Commons license, and indicate if changes were made. 
capacity are likely to determine the preference for innovation in terms of informal inbound innovation (Veronica, et al., 2017; Han and Ko, 2017). The acquisition of new knowledge and its explorations are few of the fundamental company strategies (Foster, 1986). In order to do this, firms can conduct to a successful inbound know-how transfer process and create value within open innovation (Dubickis and Gaile-Sarkane, 2017). When it is impossible to break through efficiency of parts, architecture innovation is triggered.

In this paper, I deal with architecture innovation through the concept of architectural knowledge in OSAT (outsourcing semiconductor assembly and test, hereafter OSAT). Also, this study provides the procedural framework for success on the system changes focusing product innovation process through the case. The reason choosing this case is that The K (case study target firm, hereafter The K) invented a new concept called the Vibration Feeding Flip with copper pillar flip chip (VFFPC) which has newly become key component in the Pick and Place machine. Until vibration feeding flip with copper pillar flip chip was invented, rotational flip chip mechanism had been regarded as principle operation mechanism as a dominant design for OSAT. Newness, from rotational flip chip into vibration feeding flip with copper pillar chip (VFFPC) can be regarded as radical change result from destroying the architectural knowledge.

This newness can't be called an architectural innovation according to Jelinek and Schoonhoven (1990), since it comes from sequential process to simultaneousness. In this article I focus on the innovation process at OSAT firm to investigate the knowledge exploitation as perspective of architectural innovation. In order to do this, I employ the qualitative methodology. In particular, to conduct a sophisticated investigation, over fmy interviews Ire conducted with a company's technology development engineers, including vice president, as well as a thorough literature review. In addition, internal documents of the technology development have also been utilised. This paper is constructed as follows. In Section 2, I review the existing literature. In Section 3, the semiconductor industry is analysed in detail. In Section 4, conclusions are drawn from the findings and implications are presented.

\section{Theoretical background and literature review}

Innovation is a quest into the unknown. In general, the definition of architectural innovation is either the improvement of existing parts in order to enhance the core concept of component of systems or changing the connections between the components (Henderson and Clark, 1990; Christensen, 1992; Teece et al., 1997; Tushman and O'reilly, 2002; O'Reilly and Tushman, 2008). The change in the connecting parts is accompanied by the relevant parts of the upgrade. Architecture innovation happens when improved efficiency of part is more the concern rather changing the system architecture directly. There is considerable evidence that technical innovations involve modest changes to the existing technology, but have dramatically competitive consequences (Clark, 1987). Innovation patterns deal primarily with existing technology (i.e., design, component) and new concepts that depart in significant ways from previous technology.

There is a critical concept to understand why technology is changing. That is the concept of dominant design. Dominant design is a stabilized operational principle or product architecture that gains a majority of the market (Murmann and Frenken, 
2006). An era of incremental change brings the chance for innovation. These innovations include as follows: product to process innovation (Abernathy and Utterback, 1978); a general reduction of innovativeness, such as: cost reduction; minor component and subsystem innovation. These activities can be accompanied by product customization for differentiated market segments. The reason that existing firm is inclined to focus on product innovation as opposed to innovating the architecture is because an era of incremental change is marked by organizational, social and political stabilization (Tushman and Rosenkopf, 1992). Namely, firms have a propensity for loIr level problem solving (Funk, 2003).

As mentioned above, I believed that in an era of incremental innovation, there are numerous technical innovations that involve seemingly modest changes to the existing technology, but have quite dramatic competitive consequences.

\section{Architectural innovation}

The main concern of this paper is to understand how an outsmycing firm vield as having no system knowledge can be successful in the architectural innovation by obviously changing the operational principle from existing rotational into vibrational ways for Pick-and Place instruments. For most companies, being the market dominator is the final goal. In particular, manufacturing companies (e.g., Semiconductors, key component of Information Technology and communication (hereafter, ICT)) produce the goods through numerous manufacturing processes. Innovation is intensive and focused action that can allow firms to generate new knowledge and to apply it to new productions (Fagerberg et al., 2005). Newness is not always innovation. In particular, the semiconductor industry tends to innovate persistently in the high-tech industry (Jelinek and Schoonhoven, 1990). Typically after dominant designs emerge, existing firms are likely to set up incremental innovation (Anderson and Tushman, 1990). For incremental change, product architecture remains stable (Henderson and Clark, 1990). What take places for firms after a dominant design (Tushman and Murmann, 1998) emerges, at least until the next technological disruption, is the main concern in this paper. To achieve these research goals, I take the case of the Pick-and Place Machine (semiconductor packaging machines) that is used to protect chips and core electron elements (e.g., computer, mobile phone, camera etc.).

Semiconductors are sophisticated and embody the complicated characteristics of the manufacturing process, which is further disseminated into a subdivided production process. The characteristics of this process have necessitated the division of the manufacturing into two parts, the front-end and back-end processes. In this case study, I deal with an innovation case in the aforementioned back-end process. The back-end process manufacturer OSAT has become a fierce market competitor because of the expansion of semiconductor packaging technology. Thus, OSATs have packaged chips from wafer being used as a component in numerous electronics products (e.g., Smart phones, mobile phones, appliances, computer, and etc.).

Architectural innovation changes the way in which the components of a product are linked together, while leaving the core design concepts and thus the basic knowledge underlying the components, untouched (Henderson and Clark, 1990). Also, architectural innovation destroys the usefulness of a firm's architectural knowledge but preserves the usefulness of its product's component knowledge. Henderson and Clark 
(1990) also defined a component as a physically distinct portion of the product that embodies a core design concept and performs well- defined function. Considering that what the definition of architectural innovation (Henderson and Clark, 1990; Christensen, 1997) is, the distinction between incremental innovation and radical innovation, radical innovation establishes a new dominant design and, hence, a new set of core design concepts embodied in components that are linked together in a new architecture.

Figure 1 shows the classification of innovation type by Henderson and Clark (1990). Henderson and Clark (1990) suggested that innovation can change when the core design concept of technology, and innovation type can be differentiated relationship the core design. The distinction from Modular innovation and Incremental innovation depend on how much intensity of degree of core concept technology. In the same way, the differentiation between Architecture innovation and Radical also depend on how much of degree of modular innovation.

Successful product development requires two types of knowledge: component knowledge and architectural knowledge. The former is the knowledge about each of the core design concepts and the way in which they are implemented in a particular component. The latter is the knowledge about the ways in which the components are integrated and linked together into a coherent whole. The essence of an architectural innovation is the reconfiguration of an established system to link together existing components in a new way (Henderson and Clark, 1990). They also note that architectural innovation is often triggered by a change in component design- perhaps size or some other subsidiary parts of its design. Architectural innovation presents established firms with a more subtle challenge. Subtle challenge comes from aggregated knowledge in existing firms.

\section{Architecture knowledge}

Henderson and Clark (1990) suggested that the technological knowledge behind innovation can be divided in two dimensions: knowledge of the components and knowledge of the linkage between them, called architectural knowledge. As the innovation consists of a new idea and its implementation into a new product, process or service, innovation is not a one-time phenomenon. Rather, innovation is a long time cumulative process of a great number of organizational decision-making process, ranging from the phase of generation of a new idea to its implementation phase. As I reviewed, knowledge is key component to innovation; knowledge flows related to

\begin{tabular}{c|c|c|}
\multicolumn{1}{c}{} & \multicolumn{1}{c}{ Reinforced } & Overturned \\
\cline { 2 - 3 } Unchanged & $\begin{array}{c}\text { Incremental } \\
\text { Innovation }\end{array}$ & $\begin{array}{c}\text { Modular } \\
\text { Innovation }\end{array}$ \\
\cline { 2 - 3 } Changed & $\begin{array}{c}\text { Architectural } \\
\text { Innovation }\end{array}$ & $\begin{array}{c}\text { Radical } \\
\text { Innovation }\end{array}$ \\
\cline { 2 - 3 } & & \\
\cline { 2 - 3 } & &
\end{tabular}

Fig. 1 A frame work for defining innovation 
innovative activities are a core component of the first major implementations dealing with the details and specificities of how innovations are being created and how the innovation process can best be organized (Witt, 2016).

Henderson and Clark (1990) suggested that, concerning architectural innovation and knowledge, architectural innovation destroys the usefulness of a firm's architectural knowledge but preserves the usefulness of its knowledge about the product's components. In case of radical innovation, as mentioned above, the firm uses totally different knowledge. Namely it creates new challenges for established firms, since it destroys the usefulness of their existing capabilities (Henderson and Clark, 1990). There are two dimensions that I can use to separate an incremental from a radical innovation: The first is an internal dimension, based on the knowledge and outsourcing involved. An incremental innovation will build upon existing knowledge within a certain company, meaning it will be competence-enhancing. A radical innovation, on the other hand, will require completely new knowledge and will be, therefore, competencedestroying. The second dimension, the external one, differentiates the innovation based on the technological changes and on the impact upon the market competitiveness.

An incremental innovation will involve modest technological changes and the existing products on the market will remain competitive. A radical innovation will instead involve large technological advancements, rendering the existing products non-competitive and obsolete.

I define 'architectural knowledge' to be a major modification of how components in a product or system are linked together, in the product development process. Furthermore, in essence, the tacit (i.e., uncodified, experience based) technical knowledge is exploited to development of components in the product innovation process. Han and Cho (2015) suggested PSE Platform model contained Killer contents as a concept of architectural knowledge and technology component that is functionally interdependent with other components.

Existing firms should confront the market environment or technology in order to pioneer the markets. In the same context, firms should build knowledge and capabilities around the recurrent tasks they perform that are shaped by the intraexperience with an evolving technology. Architectural knowledge is critical for keeping innovation capabilities and to cope with emerging complexities.

\section{Analysis of semiconductor packaging industry}

\section{Study methodology}

In order to achieve the research aims, this study analyses an example of innovative activity through The K company (hereafter, The K), a global semiconductor packaging firm in South Korea. Innovation process at the firm level takes a long time to reach the market, therefore qualitative cast study methodology is more appropriate (Baxter and Jack, 2008). According to Yin (2003)'s study regarding when to use a case study, it should be considered when: (1) the focus of the study is to answer "how" and "why" questions; (b) you can't manipulate the behaviour of those involved in the study; (c) you want to cover contextual conditions because you believe they are relevant to the phenomenon under study; (d) the boundaries are not clear between phenomenon and context. Since this paper deals with the why and how The K should implements innovation, and I can't manipulate the data, case study methodology is appropriate 
(Yin, 1994, 2003). That is the participant and observable case study (Yin, 2003). When taking into consideration the prudent context of innovation process a single case study is adaptable. Semi-structured interviews Ire conducted to recognize different role within OSAT: content providers. Interviews Ire conducted to the Research and Development division managers, especially product managers. The conversations during the interviews has focused on motivation of new developments, the role of knowledge stock, perceived threats and strengths of the firm. After giving the promise that company's name may not be disclosed in the paper, and that interview data only can be utilized as complement of prior literatures I can conduct to interviews. Respondents Ire asked about the story of the innovation experiences they were involved in and the story of the recent semiconductor industry. In particular, I focused my interviews on the development of new idea and knowledge exploitation. I asked respondents how to get the external knowledge and technology with respect to the Pick-and-Place machine's key core knowledge. The author acknowledges that this process could have some biases, but it offers considerable advantages over other methods, particular during the exploratory phase of the research. I recorded interviews where respondents permitted. This result is presented based on the interview data and exploratory data.

To collect the data, I utilized previous literature, periodicals, and semiconductor related professional materials including paper covering opinion leaders. Furthermore, in order to learn about the decision making process and professional working levels, four interviews were conducted from April to December of 2015.

\section{Overview of the $\mathrm{K}$}

Market structure always changes due to both the evolution of technology and market demand. As mentioned above, a semiconductor is a product with the typical manufacturing characteristics that also undergoes a subdivided manufacturing process. The manufacturing process is divided into front-end and back-end process to produce the final product. In other words, there is a basic process for manufacturing a semiconductor and a back-end process that provides protection (packaging) to allow consumers to easily use the semiconductor that has been produced. As The $\mathrm{K}$ is the largest company with respect to a back-end process firm, in Korea (hereafter The K) is the one of the largest firms globally. Founded in 1968, as one of the world's largest suppliers of outsourced semiconductor advanced packaging design, The $\mathrm{K}$ has been implemented to make these innovations a reality. The $\mathrm{K}$ was at the frontier of the semiconductor industry in Korea, in spite of numerous difficulties and the bad environment in manufacturing at the time. When $\mathrm{K}$ starts to business, numerous experts were sent to America to learn how to operate the Pick and Place machine. In the initial stage in 1980s, K company had built R\&D division to try to learn the technologies and develop the new knowledge, regarding the operating the Pick and Place. Since 2000s few researchers chosen for special experts have been sent doctoral course domestic and oversea universities in order to cultivate the new knowledge.

\section{Back-end process of semiconductor (packaging)}

As mentioned above, a semiconductor is a product with the characteristics of a typical manufacturing that undergoes a subdivided manufacturing process. The characteristics of such manufacturing process are divided into front-end process and back-end process 
to produce the final product. In other words, there is a basic process for manufacturing a semiconductor and a back-end process that provide protection (packaging) to allow consumers to easily use the semiconductor that has been produced.

It is necessary to protect the semiconductor chip from the external environment. For this reason, packaging (post-process) is an important part in semiconductor manufacturing. Electronic packaging provides the interconnection from the IC the printed circuit board (PCB) as well as desired mechanical and environment protection to ensure reliability and performance.

To perform such back-end processes, many types of equipment are required, as well as various raw and subsidiary materials. Information related to Machine, Material, Man, and Method of Process costs are classified as 4 M (Machine, Material, Man, and Method) factors. In addition, the packaging assembly process requires expensive equipment and technology, as well as strict quality control for each process. The packaging industry must have equipment that can perform ultra-precision work and knowledge to the industry standards. Also, the equipment needs continuous improvement because of the rapid technological development of semiconductor manufacturing (front-end process). In addition, there is also a need to manage ultra- precision $(50 \mu \mathrm{m})$ technology because of the product's characteristics. As a result, it requires ceaseless cutting-edge technology. The emergence of a new concept or technology is usually a period of considerable confusion. The Pick and Place machine is has a key role in packaging the die from the wafer. Careful die (or chip) handling is extreme to maintain quality and good die yields from the wafer once it has been sawn (Fig. 2).

Using a Pick and Place machine, workers to apply the absolute minimum contact and relative force require to remove die from the foil ring frame after sawing. Even though there are circumstances where a degree of manual removal is necessary, it is preferable to opt for an automated process as the possibilities of mechanical damage to the die are greatly reduced. The reason that Pick and Place machine automation is important for packaging is to deal with high volumes and enable faster output turn-around which is simply not possible otherwise. A good example to use would be a small transistor. According to the interviews even the most dexterous and experienced clean room operative could not hope to manually remove 1750 die in an hour. The architectural knowledge of the Pick and Place automation is that the operator manually adjusts the $\mathrm{X}$ and $\mathrm{Y}$ coordinates to the centre on a die by viewing it on a magnified screen. The actual die are removed from the foil through the use of single or multiple ejector pins which push up from under the foil and release the die by applying pressure to the backside. To collect the raised die, a vacuum powered mechanical arm sweeps across,

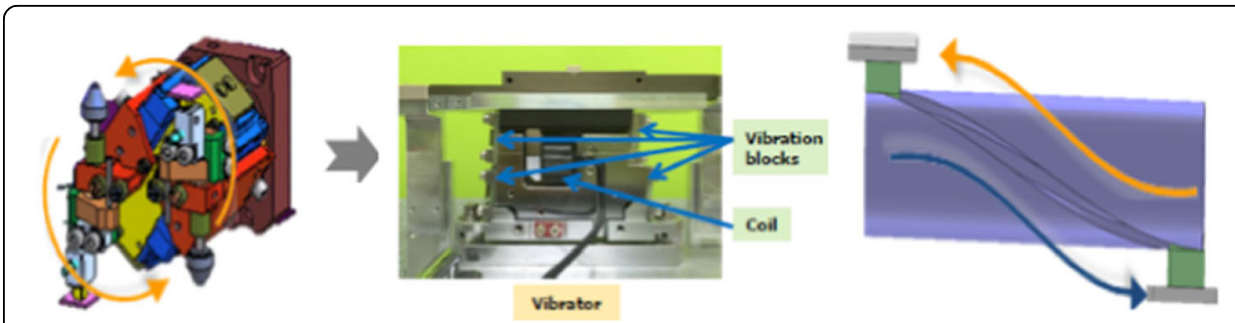

Fig. 2 Pick-and-place Flip (Mechanical Rotation Method $\rightarrow$ Vibration Feeding Method) 
pick up the die and releases it into the carrier. The Pick and Place machine requires expert calibration to set-up, operation speed is the important competitiveness aspect (Fig. 3).

The packaging industry, with the diversification in the package form of recent mobile devices and information equipment market, is more compact, composite and diversified. Currently, technology has been progressed in the form of CSP (Chip Scale Package), MCP (Multi Chip Package), and SIP (System In Package). In other words, the packaging industry is changing around the high value-added products.

\section{The evolution of component and architectural knowledge}

As mentioned above, the change in the connecting parts is accompanied by the relevant part of the upgrade because architecture innovation is likely to happen when improving the efficiency of the part is more of concern than changing the system architecture directly (Handerson and Clark, 1990). Two concepts are critical to understanding the ways in which component and architectural knowledge are managed inside a firm. Technical evolution is usually characterized by periods of great experimentation followed by the acceptance of dominant design (Henderson and Clark, 1990). The second concept is that organizations build knowledge and capabilities around the recurrent tasks they perform (Nelson and winter, 1982).

In 1940s, a printed circuit board (PCB) was created. It reduced the increasing complexity of attempting to wire circuits manually. However, as PCBs became more prevalent and advanced, it also became difficult to quickly and accurately produce circuit boards in large quantities. To solve these difficulties, the Pick and Place method, with its ability to place a large quantity of components on board extremely quickly arrived. Pick and Place machines all function by picking up a component in one place and putting it in another, instead of using fingers or tweezers like a human operator would use. The variety of situations in which the Pick and Place is used has created in interesting smorgasbord of styles for the picking and placing concept, though all operate according to a set of basic principles.

In the beginning of 2000s, the semiconductor utilisation field rapidly developed in the IT industry, and it have been deployed further in the fabrication process field through diversification. These led to the growth of a huge foundry and back-end process. In accordance with the development trend of electronic products, technology development has been carried out in the miniaturisation and highly integrated

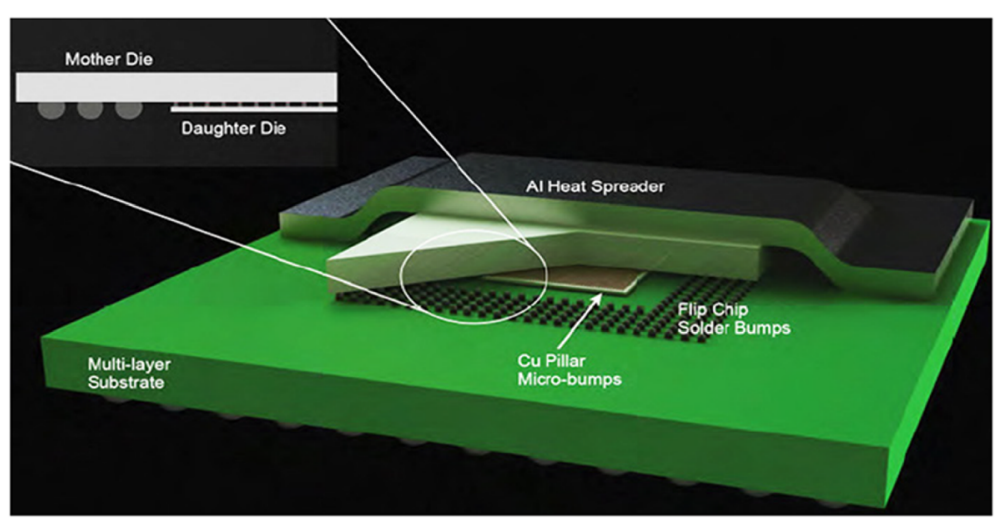

Fig. 3 Die size and Chip stack process 
semiconductor packaging. As such, the semiconductor packaging technology has become increasingly important.

To overcome limitation of fabrication process technology, the semiconductor industry is researched from various angles. Above all, it is focused on the development of packaging technology represented by SIP. The example of specific SIP implementation is TSV, FOWLP. Past packaging is to simply protect circuit but newest package is develop to meet ambivalent needs of low power, high performance and compact.

As mentioned above, at the beginning of 2000s, Single Head architectural technology was adapted for use in the Pick and Place machine. Single Head is the general acceptance of particular product architecture and is characteristic of technical evolution in a Pick and Place machines. Single Head architectural technology actually dominated the Pick and Place machine market. A dominant design often emerges in response to the opportunity to obtain economies of scale or to take advantage of externalities (Arthur, 1988). The $\mathrm{K}$ as a front runner of OSAT, adapted it in spite of having plenty of its own technologies because customers such as Samsung has strongly required it. Figure 1 presents the operation principle of Single Head Pick and Place Module. By utilizing the single head, Pick and Place machines pick the die from on wafer and placing them in the holes. Single Head technology is principle operation method, thus architecture technology. The $\mathrm{K}$ having accumulated knowledge about the operation principle of the Pick and Place machine began the innovation, because single Head component had a time lag during the process from picking the die to placing it the hole. Also the time required to move the die hindered quality control. Real time product inspection is much more important for OSATs.

The innovation team at The $\mathrm{K}$ tried to shorten the times, from picking to placing. Originally, The $\mathrm{K}$ was not a firm that manufactured these machines rather only one of the users of it. At that time, The K's biggest risk was losing the frontier's advantage due to chasing the latecomers, by using the Pick and Place machines equipped with Single Head technology. In addition, according to the IC chip's minimization propensity, The $\mathrm{K}$ strongly felt that it could create the new Pick and Place machines with its accumulated architectural knowledge through the strategic alliance with a firm that only manufactured the production machines. The main component was transferred from Single Head to Double Head. But, despite several tries and a large amount of $R \& D$ expenditure, new machines were delayed due to the weak infrastructure of the domestic firms that produced the machines. Figure 4 shows how Pick and Place operates with the Double Head component and vibrational feeding. Unlike a Single Head component technology, one head used for picking the wafer and the other used moving it from a placement to Real box. Double head offers variety benefits compared to Single Head components: (1) shorten the product times; (2) decrease the ratio of fraction defective. In order to produce one single semiconductor customer can utilize, numerous production process is necessary.

The following innovative Die Flip Design is for the Die Flip Operation as the Feeding Type that uses vibration. It is an innovative improvement over the Flip Operation of an existing Rotary Operation, as it overcomes the limitation of Tact Time through the mechanical Flip Operation of existing equipment. Moreover, it improves the UPH, which is the core of the pick-and-place equipment by up to $150 \%$. Thus, it expects a 


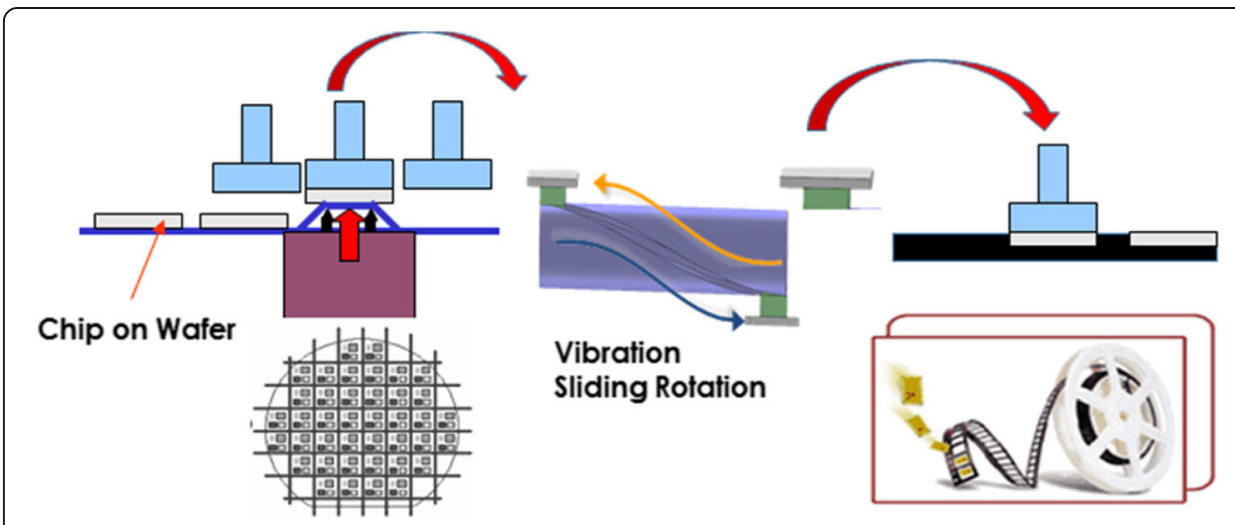

Fig. 4 Multi Pick Up and Vibration Flipper Module in Double Pick and Place Module

very large effect in terms of strengthening the quality in accordance with declining the Tact Time. In addition, it reduces the error rate generated during the operation of the equipment by more than $90 \%$.

It is more important for OSAT firms to find the fraction defective during the production process than any others. Double head component enable to inspect the chip unlike single Head. Moreover, there are two pick and place heads on machine, the production efficiency is improved up to more $60 \%$ than with one head. In spite of the innovative input, The $\mathrm{K}$ failed because their competitor already developed a similar product. At the end of 2010s, competition was more heated up for OSAT due to Double Head component. The $\mathrm{K}$ established a new organization to implement the innovation beyond the double head component. This led to the dual Flipper Module in the Double Pick and Place machine. With the ongoing expansion of the smart phones, digital cameras and other electronic based products, the flip chip revolution is in full swing. Time to market and volume production are more important than ever. This flip chip technology drives the need for production equipment including flip chip bonders. A key advantage of flip chip is size. Flip chip does not require peripheral space for the wire bond. They can be made smaller than wire bond packages with a similar Input and Output count. For die with Input and Output count, flip chip technology offers large space savings because the I/O can be arranged in an array on both die and substrate. This eliminates the need for traces to the chip edge form internal interconnect points. A key advantage of dual Flipper is improved performance because it provides improved number of $\mathrm{I} / \mathrm{O}$, plus the concentration of more signal, ground and power connections in smaller area, in terms of rotating the double Pick and Places. This process eliminated die attach wire bonding. Assembly time, the total number of process steps, overall capital equipment cost, the number of pieces of equipment as well as other factors effected by flip chip technology resulted in a reduced cost.

At the end of 2015, The $\mathrm{K}$ had gathered a great deal of architectural knowledge. Using this architectural knowledge, Pick and Place operation principle was changed from a rotation flip into a vibrated feeding flip. Vibrated feeding flip module was created at first by using the accumulated component knowledge. It was possible due to The K's architectural knowledge. Special organization team aiming at the development new equipment had traced the architectural knowledge beginning from knowledge at the 2000s. Finally the research team reached the conclusion that the creation of this 
new component would bring about time savings in dual pick and Place machines. The research team destroyed the existing concepts. If die flip could be picked up and moved simultaneous to the real box by the sliding through vibrator's power, it could not only overcome the time limitation of rotating concept, but brings new architectural knowledge. Key problem The $\mathrm{K}$ confronted is to innovate new technology that can protect chipping of the chip in the sliding process because of friction. This difficulty could be solved by adapting the cooper plating. In this process, innovation team decided to destroy the accumulated knowledge about the component way of the Pick and Place (i.g., operational mechanism- from consecutive way into vibrationSimultaneous way). Consequently, this architectural knowledge enables The $\mathrm{K}$ to regain the competitiveness in OSAT.

\section{Summary}

My research questions are geared to discover how architectural knowledge is managed, and brings about product innovation (development of new production instruments) in the aspect of architectural in nature. Semiconductors have the characteristics of a typical manufacturing process, which undergoes a subdivided production process. The characteristics of its process have necessitated the division into front-end process and back-end process, after which the final product is produced. In this case study, I deal with an innovation case of the aforementioned back-end process. In particular, this study analysed the process of overcoming the technological restraint through product innovation.

Different types of innovation require other types of knowledge (Schilling 2008). Technology innovation is the knowledge of component, and links between components, methods, process, and techniques that go into a product (Popadiuk and Choo, 2006). The K needs innovation for its sustained growth through the company's performance (Cohen and Levinthal 1989). As innovation outcome leads the performance of companies, such achievements need to be part of the creation of the companies' technical capabilities (Geroski and Toker 1996). In the process of innovation, Afuah (1998)'s argumentation regarding to the utilization of knowledge, knowledge of component, linkages between component, methods, process and techniques is critical to innovation.

Judging from innovation pattern of The $\mathrm{K}$, even though the technical life span of a packaging instrument is $3-5$ years, The $\mathrm{K}$ has accumulated architectural knowledge. According to the interview data, The $\mathrm{K}$ has been pursued the knowledge under the motto that 'knowledge is a construction of reality'. Knowledge can be accumulated by joint activities, shared experiences, spending time in the same environment, apprenticeship, observing how the practice works, etc. It involves capturing knowledge through direct interactions with suppliers and customers. In particular, dialogue with customers such as Apple, Samsung or interaction with external experts, and the creation of a work environment that allows camaraderie with external partners. Before The K met difficulties at the late of 1990s, The K tried to maximize their architectural knowledge. In order to internalize the knowledge, a variety of activities were utilized: technology training programs, cross functional development team for the purpose of obtaining the knowledge by search and sharing of new values and thoughts, and the facilitation of prototyping and benchmarking. 
From the findings, I can see that once dominant design, Pick and Place had been accepted, engineers are not likely to re-evaluate like the radical innovation (e.g., from PCB to Pick and Place way). Engineers tried to refine the initial set of components and tried to shape component improvements in the component within the framework of a stable architecture by using architectural knowledge. New component knowledge becomes more valuable to a firm than new architectural knowledge because completion between designs revolves around refinements in particular components (Henderson and Clark, 1990). The $\mathrm{K}$ have strongly focused on development of customised equipment to fit the needs of a customer since in an industry characterized by a dominant design (Pick and Place) architectural knowledge is stable (Henderson and Clark, 1990; Christensen, 1997). Incremental innovation are designed to meet existing customer's needs (O'Reilly and Tushman, 2008) while radical innovations are designed to meet the needs of emergent customers (Benner and Tushman, 2003).

The concept of competency enhancing innovation versus competency destroying innovation was effective way to explaining the innovation success of firms in the face of breakthrough innovation (Tushman and Anderson, 1986). If innovations are competence destroying, they change the basic performance metrics rendering established technologies obsolete and destroying the value of incumbent links to existing customers (Danneel, 2004). By taking into consideration Danneel's (2004) argument, The K's innovation is the competency enhancing innovation.

By considering the ability to leverage architectural knowledge embedded in structure and information processing procedures (Henderson and Clark, 1990), The K's product innovation, namely from rotation flip chip chanced into vibration feeding flip. The following innovative Die Flip Design is for the Die Flip Operation as the Feeding Type that uses vibration. It is an innovative improvement over the Flip Operation of an existing Rotary Operation, as it overcomes the limitation of Tact time through the mechanical Flip Operation of existing equipment. Moreover, it improves the UPH, which is the core of the pick-and-place equipment by up to $150 \%$. Thus, it expects a very large effect in terms of strengthening the quality in accordance with declining the Tact Time. In addition, it reduces the error rate generated during the operation of the equipment by more than $90 \%$. This VFFPC become the new dominant technology in Pick-and-Place machine. The $\mathrm{K}$ has become a first mover through architectural innovation.

\section{Conclusions and implications}

Changing from Rotation Method to Vibration Feeding flip in the Pick and Place machines is not only an incremental innovation but also a modular innovation, using architectural knowledge in an internal firm in terms of overcome the discontinued technology. Since architectural knowledge is stable once a dominant design has been accepted, it can easily be embedded in these forms and thus becomes implicit (Henderson and Clark, 1990; O'Reilly and Tushman, 2008; Plessis, 2007; Yoon and Jeong, 2017). Firms that are actively engaged in incremental innovation, which occurs within the context of stable architectural knowledge are thus likely to manage much of their architectural knowledge. By considering the classification of innovation from Henderson and Clark (1990; Nonake and Tekeuchi, 1995; Senge, 1990; Lin, 2007; Yoon and Jeong, 2017). The K's innovation can be classified as modular innovation. By 
internalizing architectural knowledge, engineers use strategies to find problem-solving within components. Problem solving strategies also reflect architectural knowledge about the component linkages that are crucial to the solution of routine problem (Henderson and Clark, 1990).

From the case analysis, architectural knowledge is the important role to innovation, even though it has not been used for radical innovation. The K had changed particularly the way in which the Pick and Place system was integrated with the rest of the aligner. These changes dealt with component interactions. As a result, Pick and Place machines, particularly the second-generation (i.e., Double Head) machines, were incremental innovation.

However, the gap between the rotational and vibration method must be radically different approach. Thus, the successful design new ways even though it could not be classified as radical innovation (Freeman, 1982), requires both the acquisition of some new architectural knowledge on how to build a more sophisticated stable gap-setting mechanism. Actually, The $\mathrm{K}$ is not a firm that makes production equipment but rather a customer of the firm that produces factory machines. By considering that architectural innovation is often trigged by existing components perhaps size or some other subsidiary parameter of its design (Henderson and Clark, 1990; Thshman and O'Reilly, 1997), The K's innovation also could be classified as radical innovation rather modular innovation.

Based on analysis, this study suggested the following implications: (1) managing architectural knowledge by accumulating component knowledge; (2) sharing the knowledge intra firm. Radical innovations impact industrial landscapes. But, incumbent firm has focused on surviving and prospering rather destroy the usefulness of existing capabilities. However, in order to survive, firm have willingness to destroy their usefulness capabilities. Architectural knowledge is the way in which the components are integrated and linked together into a coherent whole (Henderson and Clark, 1990). The K, has been accumulated knowledge, and implemented incremental innovation by using architectural knowledge. This paper contributes to the fact that architectural innovation which had been regarded as possible at only the system firm can occur in small firm like outsourcing firm. Overall I can say that the Incremental-Radical dichotomy helped not to explain some innovation patterns, and there was favorable evidence for the model within most mature industries. More importantly, knowledge exploitation and explore complementary asset are fundamental resources for both Incremental innovation and radical innovation.

This paper has several limitations. This type of single case study was limited and the result cannot be generalized. In fact, identifying the case and the specific type of case study is unclear. In order to avoid this limitation, I should collect multi-data and multi cases in OSAT for further research. One of the common pitfalls associated with using a single case study is that there is a tendency for researcher to attempt to answer a question that is too broad or narrow. The author acknowledged that this finding can't have an explicit discrimination based on categorized knowledge exploitation since semiconductor industry has a variety of value chains. Moreover, since sophisticated manufacture process related to front-end process and back-end process is necessary in semiconductor industry sector, it is hard to articulate knowledge which is needed for each process. Last but not least, this paper has obvious contribution in that knowledge's destruction among accumulation and exploitation is critical for innovation success regardless of innovation types. 


\section{Acknowledgements}

This work was supported by 2017 Hongik University Research Fund.

\section{Competing interests}

The author declares that she has no competing interests.

Ethics approval and consent to participate

This study is free from ethics approval.

\section{Publisher's Note}

Springer Nature remains neutral with regard to jurisdictional claims in published maps and institutional affiliations.

Received: 14 April 2017 Accepted: 23 August 2017

Published online: 06 September 2017

\section{References}

Abernathy, WJ, Utterback, J (1978). Patterns of industrial innovation, Technology Review, June-July, 40-47.

Afuah, A. (1998). Innovation management: strategies, implementation and profits. New York: Oxford University Press.

Anderson, P., \& Thushman, M. L. (1990). Technological discontinuities and dominant designs: a cyclical model of technological change. Administrative Science Quarterly, 35, 604-633.

Arthur, B. (1988). Competing technologies: an overview. In G. Dosi et al. (Eds.), Technical change and economic theory. New York: Columbia University press.

Baxter, P., \& Jack, S. (2008). Qualitative case study methodology: study design and implementation for novice researchers. The Qualitative Report, 13(4), 544-559.

Benner, M. J., \& Tushman, M. L. (2003). Exploitation, exploration, and process management: the productivity dilemma revisited. Academy of Management Review, 28(2), 238-256.

Bozdogan, K., Deyst, J., Hoult, D., \& Lucas, M. (1998). Architectural innovation in product development through early supplier integration. R\&D Management, 28(3), 163-173.

Christensen, C. M. (1992). Exploring the limits of the technology S-Curve, Part 2: architectural technologies. Production and Operation Management, 1, 358-366.

Christensen, C. M. (1997). The innovator's dilemma: when new technologies cause great firms to fail. Boston: Harvard Business School Press.

Clark, K. B. (1987). Managing technology in international competition: the case of product development in response to foreign entry. In M. Spence \& H. Hazard (Eds.), International Competitiveness: 27-74. Cambridge: Ballinger.

Cohen, W. M., \& Levinthal, D. A. (1989). Innovation and learning: the two faces of R\&D. The Economic Journal, 99(397), 569-596.

Danneels, E. (2004). Disruptive technology reconsidered: a critique and research agenda. Journal of Production Innovation Management, 21, 246-258.

Dosi, G. (1982). Technological paradigms and technological trajectories. A suggested interpretation of the determinants and directions of technical change. Research Policy, 11, 147-162.

Dubikis, M., \& Gaile-Sarkane, E. (2017). Transfer of know-how based on learning outcomes for development of open innovation. Journal of Open Innovation: Technology, Market, and Complexity, 3, 4. doi.org/10.1186/s40852-017-0053-4

Fagerberg, J., Mowery, D., \& Nelson, R. R. (Eds.). (2005). The Oxford handbook of innovation. Oxford: Oxford University Press.

Foster, R. (1986). Innovation: the attacker's advantage. New York: Summit Books.

Freeman, C. (1982). The economics of industrial innovation (2d ed.). Cambridge: MIT press.

Funk, J. (2003). Standards, dominant designs and preferential acquisition of complementary assets through slight information advantages. Research Policy, 32, 1325-1341.

Geroski, P. A., \& Toker, S. (1996). The turnover of market leaders in UK manufacturing industry 1979-86. International Journal of Industrial Organization, 14(2), 141-158.

Han, J, and Cho, O (2015). Platform business Eco-model evolution: case study on KakaoTalk in Korea. Journal of Open Innovation: Technology, Market, and Complexity, 6-16, DOI 10.1186/s40852-015-0006-8.

Han, J, and Ko, Y (2017). Knowledge exploitation and entrepreneurial activity in a regional Innovation system: first adaption of RFID at Kumho Tire in Gwangu Korea, European Planning Studies, Available at https://doi.org/10.1080/ 09654313.2017 .1282087

Henderson, R., \& Clark, K. B. (1990). Architectural Innovation: the reconfiguration of existing product technologies and the failure of established firms. Administrative Science Quarterly, 35(1), 9-30.

Hommels, A., Peters, P., \& Bijker, W. E. (2007). Techno therapy or nurtured niches ? Technology studies and the evaluation of radical innovations. Research Policy, 36, 1088-1099.

Jelinek, M., \& Schoonhoven, C. (1990). The innovation marathon: lessons from high technology firms. Oxford: Basil Blackwell.

Lin, H. F. (2007). Knowledge sharing and firm innovation capability: an empirical study. International Journal of Manpower, 28(3-4), 315-332.

Murmann, J. P., \& Frenken, K. (2006). Toward a systematic framework for research on dominant design, technological innovation, and industrial change. Research Policy, 35, 925-952.

Nelson, R., \& Winter, S. (1982). An evolutionary theory of economic change. Cambridge: Harvard University Press.

Nonaka, I., \& Takeuchi, H. (1995). The knowledge creating company. Oxford: Oxford University Press.

O'Reilly, C., \& Tushman, M. (2008). Ambidexterity as a dynamic capability: Resolving the innovator's dilemma. In A. P. Brief \& B. M. Staw (Eds.), Research in Organizational Behavior vol. 28 (pp. 185-206).

Plessis, M. (2007). The role of knowledge management in innovation. Journal of Knowledge Management, 11(4), 20-29.

Popadiuk, S., \& Choo, C. W. (2006). Innovation and knowledge creation: how are these concepts related? International Journal of Information Management, 26(2), 302-312. 
Raviola, E., \& Dubini, P. (2015). Never say never: incumbents and newcomers in presence of an architectural innovation. Journal of Media Business Studies, 5(1), 95-212.

Schilling, M.A. (2008). Strategic management of technology innovation. New York: McGraw Hill.

Senge, P.M. (1990). The fifth discipline: the art \& practice of the Learning Organization. New York: Currency Doubleday.

Teece, D., Pisano, G., \& Shuen, A. (1997). Dynamic capabilities and strategic management. Strategic Management Journal, 18(7), 509-533.

Tushman, M., \& Anderson, P. (1986). Technological discontinuities and organizational environments. Administrative Science Quarterly, 31, 439-465.

Tushman, M., \& Murmann, J. (1998). Dominant designs, technology cycles, and organizational outcomes. Research in Organizational Behavior, 20, 231-266.

Tushman, M., \& O'Reilly, C. (1997). Winning through innovation: a practical guide to leading Organizational change and Renewal. Boston: Harvard Business School Press.

Tushman, M., \& O'Reilly, I. I. I. (2002). Winning through innovation. Boston: Harvard Business School Press.

Tushman, M., \& Rosenkopf, L. (1992). Organizational determinants of Technological Change: toward a sociology of Technological Evolution, in Cummings, L. and B. Staw (eds). Research in Organizational Behavior, 14, 311-347.

Veronica, S., Manlio, D. G., Stefano, B., \& Dirk, M. (2017). Knowledge-driven preferences in informal inbound open innovation modes. An explorative view on small to medium entrepriese. Journal of Knowledge Management, Kempston, 21(3), 640-655.

Witt, $U$ (2016). What kind of innovations do we need to secure our future? Journal of Open Innovation: Technology, Market, and Complexity, 2-17. DOI 10.1186/s40852-016-0043-y.

Yin, R. K. (1994). Mastering the dynamics of innovation. Cambridge: Harvard University press.

Yin, R.K. (2003). Case study research: design and methods. New York: Sage Publications.

Yoon, S, and Jeong, S (2017). Effects to implement the open-innovation, coordinative strategies between manufacturer and retailer in reverse supply chain. Journal of Open Innovation: Technology, Market, and Complexity, 3-2. DOI 10. 1186/s40852-017-0054-3.

\section{Submit your manuscript to a SpringerOpen ${ }^{\circ}$ journal and benefit from:}

- Convenient online submission

- Rigorous peer review

- Open access: articles freely available online

- High visibility within the field

- Retaining the copyright to your article 